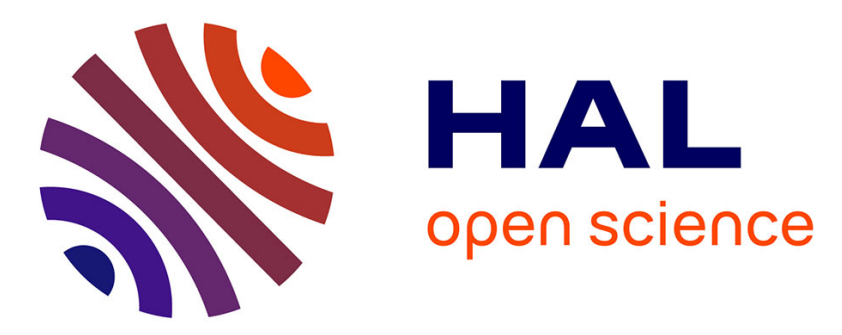

\title{
Merging and Splitting of Plasma Spheroids in a Dusty Plasma
}

\author{
Maxime Mikikian, Hagop Tawidian, Thomas Lecas
}

\section{To cite this version:}

Maxime Mikikian, Hagop Tawidian, Thomas Lecas. Merging and Splitting of Plasma Spheroids in a Dusty Plasma. Physical Review Letters, 2012, 109, pp.245007. 10.1103/PhysRevLett.109.245007. hal-00751707

\section{HAL Id: hal-00751707 https://hal.science/hal-00751707}

Submitted on 17 Dec 2012

HAL is a multi-disciplinary open access archive for the deposit and dissemination of scientific research documents, whether they are published or not. The documents may come from teaching and research institutions in France or abroad, or from public or private research centers.
L'archive ouverte pluridisciplinaire HAL, est destinée au dépôt et à la diffusion de documents scientifiques de niveau recherche, publiés ou non, émanant des établissements d'enseignement et de recherche français ou étrangers, des laboratoires publics ou privés. 


\title{
Merging and Splitting of Plasma Spheroids in a Dusty Plasma
}

\author{
Maxime Mikikian,* Hagop Tawidian, and Thomas Lecas \\ GREMI, Groupe de Recherches sur l'Energétique des Milieux Ionisés, \\ UMR7344 CNRS/Université d'Orléans, 14 rue d'Issoudun, BP6744, 45067 Orléans Cedex 2, France
}

(Dated: November 12, 2012)

\begin{abstract}
Dust particle growth in a plasma is a strongly disturbing phenomenon for the plasma equilibrium. It can induce many different types of low-frequency instabilities that can be experimentally observed, especially using high-speed imaging. A spectacular case has been observed in a Krypton plasma where a huge density of dust particles is grown by material sputtering. The instability consists of well-defined regions of enhanced optical emission that emerge from the electrode vicinity and propagate towards the discharge center. These plasma spheroids have complex motions resulting from their mutual interaction that can also lead to the merging of two plasma spheroids into a single one. The reverse situation is also observed with the splitting of a plasma spheroid in two parts. These results are presented for the first time and reveal new behaviors in dusty plasmas.
\end{abstract}

PACS numbers: 52.27.Lw, 52.35.-g

Dusty (or complex) plasmas [1] are systems where many peculiar behaviors can be experimentally observed. The presence of dust particles as an additional species in the plasma, induces new behaviors like a wide variety of instabilities that appear to be strongly nonlinear [24]. It is important to well characterize and understand these unstable phenomena because dusty plasmas are relatively often encountered in nature and industry. They are observed in astrophysics where they are involved for example in interstellar materials [5] or planetary atmospheres [6]. They are also found in industry where after being considered only as unwanted situations, they are now more involved in useful applications [7]. Nevertheless, the presence of dust particles in fusion reactors [8] like the future ITER is still a very critical issue.

To experimentally create a dusty plasma containing a huge density of dust particles (huge means that the dust particle density is not negligible with respect to electron and ion densities), the most efficient way is to grow them. Dust particles can be grown from reactive gases [9-14] or material sputtering [15-18]. In both cases, molecular precursors are injected in the reactor and are at the origin of chemical reactions initiating the growth of solid bodies in the plasma. During this growth phase, dust particles capture plasma free electrons and thus change the plasma characteristics [19-21]. When the dust particle density is huge and thus the effect on the electron population is strong, low-frequency instabilities can be observed. This phenomenon has been analyzed during dust particle growth $[15,16,22,23]$ where spatiotemporal oscillations of the plasma luminosity have been evidenced. More recently, the use of high-speed imaging improved the characterization of these instabilities and allowed to detect new behaviors. Particularly, it evidences the existence of small regions (plasma spheroids) with an enhanced emission that appear in the vicinity of the electrodes and move around the discharge [24, 25].

In this paper we show that plasma spheroids can also be observed in the dusty plasma center (Fig. 1) and, for the first time to the best of our knowledge, that they have complex interactions. Indeed, their mutual interaction gives rise to complex motions and in some cases to the merging of two plasma spheroids into a single one. The reverse situation is also encountered with the splitting of a plasma spheroid in two parts. These behaviors are observed in a capacitively-coupled radiofrequency discharge (width $4 \mathrm{~cm}$, height $3 \mathrm{~cm}$ ) in $\mathrm{Kr}$ at low pressure $(1-2$ mbar $)$ and power $(\sim 3 \mathrm{~W})$. This plasma is used to sputter a polymer material deposited on the electrodes and providing the molecular precursors giving birth to a huge density of dust particles. With respect to our previous experiments where Argon was used [27], we use $\mathrm{Kr}$ as the sputtering gas. It appears that with $\mathrm{Kr}$, the density of grown dust particles is much higher than with Ar and that the dust particle size stays relatively small (certainly below $100 \mathrm{~nm}$ due to the difficulty to observe them with laser light scattering). The dust particle formation triggers instabilities [22, 23] during which plasma
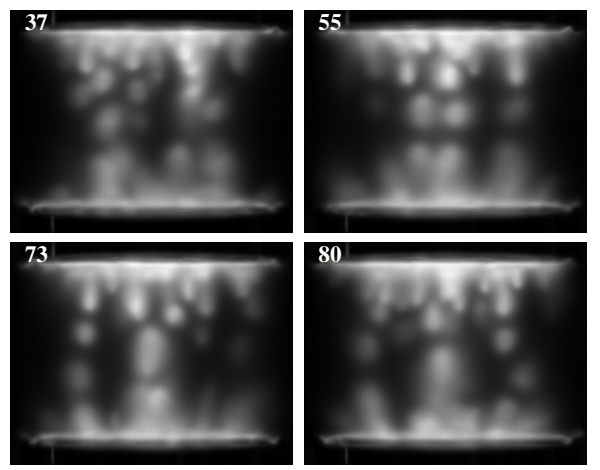

FIG. 1. Plasma spheroids in the plasma bulk: well-defined regions with an enhanced emission are clearly observed in between the electrodes (dark regions on the top and bottom separated by $3 \mathrm{~cm}$ ). The numbered frames are from a movie taken at $8000 \mathrm{fps}[26]$. 
spheroids are observed only near the electrodes $[24,25]$ or also in the plasma bulk (when dust particle density is very high) with new complex behaviors. The question of the plasma spheroid composition is posed: they can contain just plasma (as for the void [18]) or plasma and dust particles. At the moment, no clear experimental indication allows to select one of these possibilities. The plasma spheroid analyses have been performed thanks to a high-speed camera. The plasma luminosity is clearly detected up to a maximum speed of about 20000 frames per second (fps). A typical example is shown in Fig. 1 with four frames from a movie taken at $8000 \mathrm{fps}$.

From this figure and the movie [26] some general trends can be defined. The plasma spheroids have a rather homogeneous size of about a few $\mathrm{mm}$ and a comet-like shape. They come from the electrode (or sheath) regions and propagate towards the plasma bulk, their head being brighter than their comet tail. Some of them seem to stay "attached" to their place of birth thanks to this tail, while others seem to come off their tail and enter the plasma center. In Fig. 1 and in the related movie [26] some interactions between the plasma spheroids can be slightly guessed. Indeed, complex dynamics, merging and splitting of the plasma spheroids can be observed and will be more precisely highlighted in the following.

Before going deeper in the analysis of this phenomenon in dusty plasmas, it can be noted that the existence of localized structures with an enhanced emission is encountered in many different types of plasmas with certainly different physical mechanisms driving their creation and dynamics. Indeed, these regions are well-known in magnetized plasmas, especially in the context of fusion reactors. In this field they are called "blobs" and are involved in transport phenomena explaining their current intense study, both experimentally and theoretically, by many authors [28-32]. In atmospheric pressure plasmas,

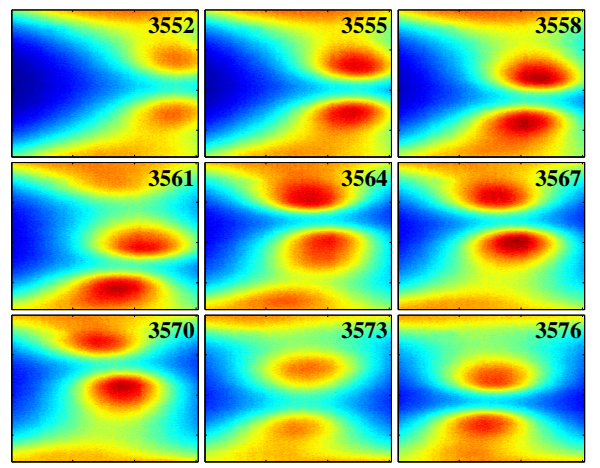

FIG. 2. (color online). Interaction between plasma spheroids leading to the up and down motion of the central spheroid. The central spheroid moves in direction of the other spheroids. Frames from a movie taken at $16000 \mathrm{fps}$ and presented in false colors from dark blue to red. Each image is about $2.3 \mathrm{~cm}$ height and $1 \mathrm{~cm}$ width. especially in dielectric barrier discharges (DBDs), these regions are called filaments and they have been shown recently to be able to interact with each other showing the merging or the splitting of these regions [33-35]. These works show phenomenological similarities with our previous observation of rotating plasma spheroids [24, 25] and with the present paper on the interaction between these structures. Similar interactions like the merging or the splitting of regions of enhanced plasma emission were also observed very recently in plasma jets where plasma streams with a comet-like shape are produced [36-39]. In these works, the well-defined comet-head (sometimes called plasma bullet) has been shown to be able to split in two parts and the merging of two bullets into a single one was also reported. In experimental conditions closer to the present study, we can report on relatively similar observations by Schulze et al. [40] where moving "plasmoids" are observed during their experiments.

In order to better observe the interactions between our plasma spheroids, another movie taken at $16000 \mathrm{fps}(60 \mu \mathrm{s}$ per frame) has been recorded. At this speed, the plasma emission appears less bright and thus the movie contrast has to be enhanced. However, this speed allows to better follow the three main interactions (dynamics, merging, splitting) of interest. This movie also corresponds to a slightly less stochastic experiment where the number of interacting spheroids is reduced compared with the case of Fig. 1, allowing an easier image analysis. The complex motions of the plasma spheroids are evidenced in the zoom shown in Fig. 2 represented in false colors (from dark blue to red). The comet-like shape is very well-evidenced in image 3552 where two plasma spheroids are getting closer. In 3555 and 3558 the upper spheroid comes off its tail and the comet head is clearly directed towards the lower spheroid. In 3564 the comet head changes its direction when the lower spheroid disappears and a new one appears on the top of the frame. The central spheroid is now going up until frame 3573 where the upper spheroid in turn disappears and a new one emerges from the bottom. Once again, a switch in

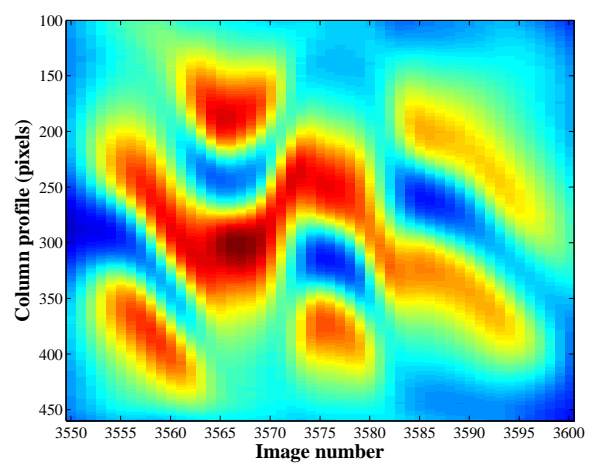

FIG. 3. (color online). Column profile (averaged over several columns) of all frames from the movie partly shown in Fig. 2. 


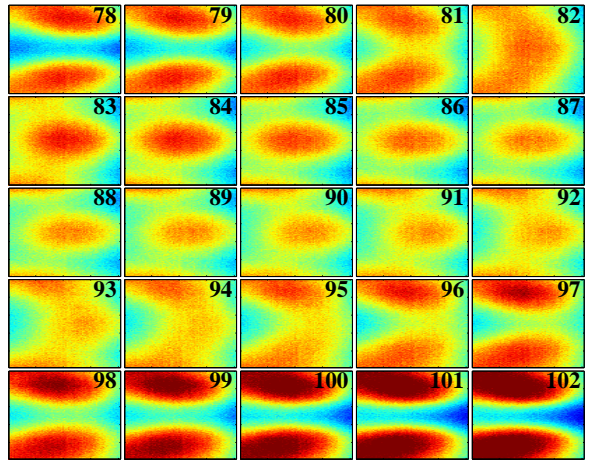

FIG. 4. (color online). Merging of two plasma spheroids quickly followed by the splitting of the newly constituted spheroid. These zoomed frames are extracted from a movie at $16000 \mathrm{fps}$ [41] and are represented in false colors. Each image is about $1.6 \mathrm{~cm}$ height and $0.5 \mathrm{~cm}$ width.

the central spheroid direction occurs.

This behavior is well observed in Fig. 3 where the column profile of all sequence frames is shown. To compensate the slight horizontal motion of the spheroids, the profile is averaged over several columns around the interaction location. The temporal mean value of the plasma emission has been also subtracted to better evidence slight emission changes. This figure clearly shows the down-up-down motion of the central plasma spheroid as a function of the appearance of other spheroids on the top or bottom. It can be also observed that the top and bottom spheroids go back towards the electrode before disappearing. The central spheroid seems to follow them and it gives an impression that it is just a global motion of all spheroids. In fact, an attraction between the spheroids can better explain the observed behavior. Indeed, a drastic reversal of the comet head position is detected when the top or bottom spheroid enters the plasma. For example, in frames 3561 to 3567 of Figs. 2-3 the change of the maximum intensity position of the central spheroid is clearly observed. The maximum is clearly on the top of the central spheroid when the top spheroid is on its way towards the center. This behavior confirms that an interaction really exists in between the spheroids and that the observed motions are not only related to a global plasma change affecting all spheroids.

Although interaction between plasma spheroids can be guessed from Figs. 1-3, a clear evidence is brought to the fore by observing the merging and/or the splitting of the plasma spheroids. These phenomena are shown in Fig. 4 where both merging and splitting are observed during a single sequence. These zoomed frames have been extracted from a movie at $16000 \mathrm{fps}$ [41]. Two clear spheroids are observed on the top and bottom of frame 78 and they are getting closer, approaching the image center up to frame 81. At this stage the merging of the two spheroids starts and continues in frame 82 . In the follow-

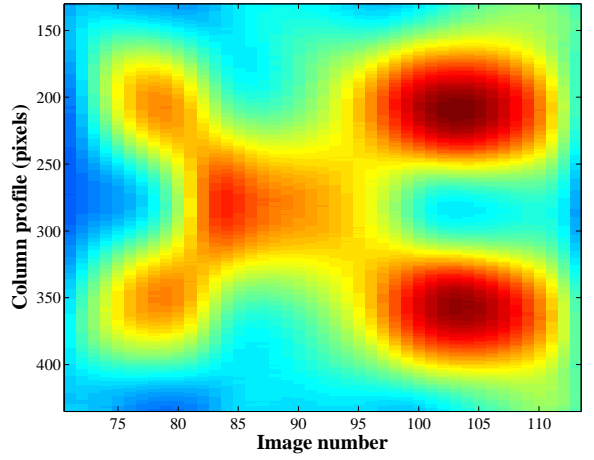

FIG. 5. (color online). Column profile (averaged over several columns) of all frames from the movie partly shown in Fig. 4.

ing frame, a single spheroid is observed with diffuse connections to the previous spheroid locations. From frame 84 up to 90 the single spheroid is nearly completely disconnected from the top and bottom parts of the frames. In frame 91 it seems that connections with top and bottom parts are activated again and the splitting starts up to frame 95 where two spheroids are again obtained. This behavior is better evidenced by using the same technique that the one shown in Fig. 3. The column profile in Fig. 5 really brings to the fore this merging/splitting sequence. It can also be observed that the two spheroids created after the splitting appear brighter, what was observed on many splitting cases. This observation and the fact that the splitting phenomenon often occurs close to the horizontal axis of symmetry of the discharge (around 260 on the y-axis of Fig. 5) are currently under investigation. This symmetry is less marked when looking at Fig. 1 and Ref. [26] where interactions also appear out of the horizontal symmetry plane.

Although getting consecutively both the merging and the splitting is quite unusual and difficult to find in the obtained movies, isolated merging or splitting are more commonly encountered. Experimental proofs of these behaviors are presented in Fig. 6 with a splitting in (a) and

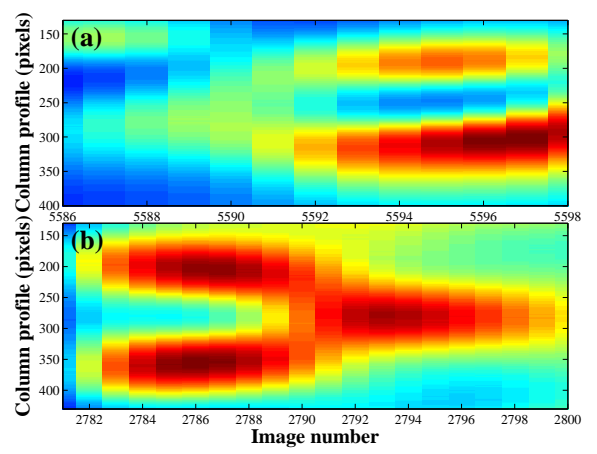

FIG. 6. (color online). (a) Splitting and (b) merging of plasma spheroids. Column profiles (averaged over several columns) in false colors from dark blue to red. 
a merging in (b) obtained during a movie at $16000 \mathrm{fps}$.

In this paper, we reported for the first time the experimental observation of the interaction of localized plasma structures (called plasma spheroids) in a dusty plasma. The case presented in Fig. 1 appears particularly rich in complex phenomena (motion, repulsion, splitting or merging) but is difficult to analyze due to the insufficient frame rate and the too big number of plasma spheroids. Thus, easier cases have been found in order to analyze these interactions. Results show that these regions of enhanced emission emerge from the electrode vicinity and propagate towards the plasma bulk where they can interact with each other leading to complex motions, repulsion phenomena or the merging of spheroids. A single spheroid can also be divided in two parts giving birth to two new spheroids. During these phenomena, the electrical characteristics of the discharge show clear instabilities. Nevertheless, a direct correlation between these measurements and the spheroid dynamics is quite difficult. First, because it would consist in comparing local behaviors (spheroids) and global electrical measurements integrating phenomena outside the camera field of view. Second, because spheroid dynamics does not necessarily change the discharge characteristics: when a spheroid is moving in between the electrodes, its "charge" is just transported from one place to another. In the case of merging or splitting, the situation is more complicated as the respective spheroid "intensities" play a role.

Similar interactions have been found in other plasma conditions like in fusion plasmas, DBDs and plasma jets for example in the context of plasma medicine. These experimental results obtained in a dusty plasma propose a new system to study these behaviors. The experimental conditions are very different in each of these fields leading to a certainly quite different physical origin of these behaviors. Nevertheless, it appears obvious that electrical effects (repulsion, polarization, ...) are the common points behind all observations. Future works will be conducted to find the physical origin of the present results obtained in dusty plasmas. These new investigations could be useful for the other fields concerned with localized plasma structures.

The authors would like to thank B. Dumax for electronic support, J.-M. Bauchire and H. Rabat for providing the high-speed camera. The PKE-Nefedov chamber has been made available by the Max-Planck-Institute for Extraterrestrial Physics, Germany, under the funding of DLR/BMBF grant 50WM9852. This work was partly supported by the French National Research Agency (ANR), project INDIGO nANR-11-JS09-010-01.

\section{REFERENCES}

* maxime.mikikian@univ-orleans.fr

[1] P. K. Shukla and B. Eliasson, Rev. Mod. Phys. 81, 25 (2009).

[2] M. Mikikian, M. Cavarroc, L. Couëdel, Y. Tessier, and L. Boufendi, Phys. Rev. Lett. 100, 225005 (2008).

[3] M. Mikikian, L. Couëdel, M. Cavarroc, Y. Tessier, and L. Boufendi, Phys. Rev. Lett. 105, 075002 (2010).

[4] S. K. Zhdanov, M. Schwabe, R. Heidemann, R. Sütterlin, H. M. Thomas, M. Rubin-Zuzic, H. Rothermel, T. Hagl, A. V. Ivlev, G. E. Morfill, V. I. Molotkov, A. M. Lipaev, O. F. Petrov, V. E. Fortov, and T. Reiter, New J. Phys. 12, 043006 (2010).

[5] E. Kovačević, I. Stefanović, J. Berndt, Y. J. Pendleton, and J. Winter, Astrophys. J. 623, 242 (2005).

[6] E. Sciamma-O'Brien, N. Carrasco, C. Szopa, A. Buch, and G. Cernogora, Icarus 209, 704 (2010).

[7] P. Roca i Cabarrocas, T. Nguyen-Tran, Y. Djeridane, A. Abramov, E. Johnson, and G. Patriarche, J. Phys. D: Appl. Phys 40, 2258 (2007).

[8] S. I. Krasheninnikov, A. Y. Pigarov, R. D. Smirnov, M. Rosenberg, Y. Tanaka, D. J. Benson, T. K. Soboleva, T. D. Rognlien, D. A. Mendis, B. D. Bray, D. L. Rudakov, J. H. Yu, W. P. West, A. L. Roquemore, C. H. Skinner, J. L. Terry, B. Lipschultz, A. Bader, R. S. Granetz, C. S. Pitcher, N. Ohno, S. Takamura, S. Masuzaki, N. Ashikawa, M. Shiratani, M. Tokitani, R. Kumazawa, N. Asakura, T. Nakano, A. M. Litnovsky, R. Maqueda, and the LHD Experimental Group, Plasma Phys. Control. Fusion 50, 124054 (2008).

[9] J. Berndt, E. Kovačević, I. Stefanović, O. Stepanovic, S. H. Hong, L. Boufendi, and J. Winter, Contrib. Plasma Phys. 49, 107 (2009).

[10] V. Massereau-Guilbaud, J. Pereira, I. Géraud-Grenier, and A. Plain, J. Appl. Phys. 105, 033302 (2009).

[11] J. Berndt, E. Kovačević, I. Stefanović, and L. Boufendi, J. Appl. Phys. 106, 063309 (2009).

[12] M. Hundt, P. Sadler, I. Levchenko, M. Wolter, H. Kersten, and K. Ostrikov, J. Appl. Phys. 109, 123305 (2011).

[13] M. Calafat, P. Yuryev, A. Drenik, A. Slim, and R. Clergereaux, Plasma Process Polym. 8, 401 (2011).

[14] I. Géraud-Grenier, R. Jaffiol, V. Massereau-Guilbaud, and A. Plain, Appl. Phys. Lett. 99, 091503 (2011).

[15] G. Praburam and J. Goree, Phys. Plasmas 3, 1212 (1996).

[16] D. Samsonov and J. Goree, Phys. Rev. E 59, 1047 (1999).

[17] C. Arnas, A. Mouberi, K. Hassouni, A. Michau, G. Lombardi, X. Bonnin, F. Bénédic, and B. Pégourié, J. Nucl. Mater. 390-391, 140 (2009).

[18] M. Mikikian, L. Couëdel, M. Cavarroc, Y. Tessier, and L. Boufendi, Eur. Phys. J. Appl. Phys. 49, 13106 (2010).

[19] S. Mitic, M. Y. Pustylnik, and G. E. Morfill, New J. Phys. 11, 083020 (2009)

[20] S. Hübner and A. Melzer, Phys. Rev. Lett. 102, 215001 (2009).

[21] I. Goertz, F. Greiner, and A. Piel, Phys. Plasmas 18, 013703 (2011).

[22] M. Mikikian, M. Cavarroc, L. Couëdel, and L. Boufendi, 
Phys. Plasmas 13, 092103 (2006).

[23] M. Mikikian, L. Couëdel, M. Cavarroc, Y. Tessier, and L. Boufendi, IEEE Trans. Plasma Sci. 36, 1012 (2008).

[24] M. Mikikian, L. Couëdel, Y. Tessier, and L. Boufendi, IEEE Trans. Plasma Sci. 39, 2748 (2011).

[25] H. Tawidian, M. Mikikian, L. Couëdel, and T. Lecas, Eur. Phys. J. Appl. Phys. 56, 24018 (2011).

[26] See Supplemental Material at [URL will be inserted by publisher] for a movie extract reproduced at $15 \mathrm{fps}$.

[27] M. Mikikian, L. Boufendi, A. Bouchoule, H. M. Thomas, G. E. Morfill, A. P. Nefedov, V. E. Fortov, and the PKENefedov Team, New J. Phys. 5, 19 (2003).

[28] S. I. Krasheninnikov, Phys. Lett. A 283, 368 (2001).

[29] D. Jovanovic, U. de Angelis, R. Fedele, and F. Pegoraro, Phys. Plasmas 14, 083704 (2007).

[30] R. Maqueda, D. P. Stotler, S. J. Zweben, and The NSTX team, J. Nucl. Mater. 415, S459 (2011).

[31] D. A. D'Ippolito, J. R. Myra, and S. J. Zweben, Phys. Plasmas 18, 060501 (2011).

[32] J. R. Angus, M. V. Umansky, and S. I. Krasheninnikov, Phys. Rev. Lett. 108, 215002 (2012).
[33] I. Brauer, M. Bode, E. Ammelt, and H.-G. Purwins, Phys. Rev. Lett. 84, 4104 (2000).

[34] L. Stollenwerk, New J. Phys. 11, 103034 (2009).

[35] J. P. Boeuf, B. Bernecker, T. Callegari, S. Blanco, and R. Fournier, Appl. Phys. Lett. 100, 244108 (2012).

[36] E. Robert, V. Sarron, D. Riès, S. Dozias, M. Vandamme, and J.-M. Pouvesle, Plasma Sources Sci. Technol. 21, 034017 (2012).

[37] C. Douat, G. Bauville, M. Fleury, M. Laroussi, and V. Puech, Plasma Sources Sci. Technol. 21, 034010 (2012).

[38] Z. Bonaventura, M. Duarte, A. Bourdon, and M. Massot, Plasma Sources Sci. Technol. 21, 052001 (2012).

[39] Z. Xiong, E. Robert, V. Sarron, J.-M. Pouvesle, and M. J. Kushner, J. Phys. D: Appl. Phys. 45, 275201 (2012).

[40] J. Schulze, D. Luggenhölscher, and U. Czarnetzki, IEEE Trans. Plasma Sci. 36, 1402 (2008).

[41] See Supplemental Material at [URL will be inserted by publisher] for a movie extract. The region of interest is on the right hand part of the movie. 